\title{
Effect of the packaging and storage conditions on the coagulation activity of spray-dried salt-extracted Moringa oleifera
}

\begin{abstract}
Moringa oleifera is one of the natural coagulants considered as an alternative to synthetic coagulants. Several studies were carried out on the usage and extraction of this natural coagulant. In this study, the coagulation activity of spray-dried salt-extracted M. oleifera seeds powder was investigated under different storage conditions, packaging forms and storage duration. The spray-dried salt-extracted M. oleifera seeds powder was stored at room temperature $\left(29^{\circ} \mathrm{C}\right)$ and refrigerator temperature $\left(3^{\circ} \mathrm{C}\right)$; under different packaging forms; closed container and vacuum packed stored for 6 Wheeks. Optimization of spray-dried saltextracted M. oleifera shows that the optimal dosage is half of the nonspray-dried saltextracted M. oleifera. The results of residual turbidity of different packaging and storage conditions of salt-extracted M. oleifera show that there was no significant difference between them. The coagualtion activity decreased insiginficantly with the increase of storage duration during the study.
\end{abstract}

Keyword: Moringa oleifera; Natural coagulant; Salt extraction; Storage condition; Spray drying 